\title{
Imagining Organization through Metaphor and Metonymy Unpacking the Process-entity Paradox
}

Schoeneborn, Dennis; Vasquez, Consuelo; Cornelissen, Joep

Document Version

Accepted author manuscript

Published in:

Human Relations

DOI:

$10.1177 / 0018726715612899$

Publication date:

2016

License

Unspecified

Citation for published version (APA):

Schoeneborn, D., Vasquez, C., \& Cornelissen, J. (2016). Imagining Organization through Metaphor and Metonymy: Unpacking the Process-entity Paradox. Human Relations, 69(4), 915-944.

https://doi.org/10.1177/0018726715612899

Link to publication in CBS Research Portal

\section{General rights}

Copyright and moral rights for the publications made accessible in the public portal are retained by the authors and/or other copyright owners and it is a condition of accessing publications that users recognise and abide by the legal requirements associated with these rights.

Take down policy

If you believe that this document breaches copyright please contact us (research.lib@cbs.dk) providing details, and we will remove access to the work immediately and investigate your claim. 


\title{
Imagining Organization through Metaphor and Metonymy: Unpacking the Process-Entity Paradox
}

\section{Dennis Schoeneborn, Consuelo Vasquez, and Joep Cornelissen}

\author{
Journal article (Post print version)
}

Cite: Imagining Organization through Metaphor and Metonymy: Unpacking the Process-Entity Paradox./Schoeneborn, Dennis; Vasquez, Consuelo; Cornelissen, Joep. In: Human Relations,

Vol. 69, No. 4, 2016, p. 915-944.

DOI: 10.1177/0018726715612899

Uploaded to Research@CBS: May २016 


\title{
IMAGINING ORGANIZATION THROUGH METAPHOR AND METONYMY: UNPACKING THE PROCESS-ENTITY PARADOX
}

\author{
Dennis Schoeneborn, Consuelo Vásquez, and Joep Cornelissen
}

\begin{abstract}
Authors' note: This is the prefinal and unedited version of the following publication: Schoeneborn, D., Vásquez, C., \& Cornelissen, J. (2016). Imagining organization through metaphor and metonymy: Unpacking the process-entity paradox. Human Relations, 69(4), 915944. (see link: http://hum.sagepub.com/content/69/4/915)
\end{abstract}

\begin{abstract}
Within organization studies, Morgan's seminal book 'Images of Organization' has laid the groundwork for an entire research tradition of studying organizational phenomena through metaphorical lenses. Within Morgan's list of images, that of 'organization as flux and transformation' stands out in two important regards. First, it has a strong metonymic dimension, as it implies that organizations consist of processes. Second, the image invites scholars to comprehend organizations as a paradoxical relation between organization (an entity) and process (a non-entity). In this paper, we argue that flux-based images of organization vary in their ability to deal with the process-entity paradox, depending on the degree to which its metaphorical and metonymic dimensions are intertwined. We thus examine three offsprings of the flux image: organization as becoming, organization as practice, and organization as communication. We compare these images regarding their metaphor-metonymy dynamics, the directionality of their process of imagination, and the degree of concreteness of the resulting figure. We contribute to Morgan's work, and to organization studies more generally, by offering an analytical grid for unpacking different processes of imagining organization. Moreover, our grid can help explain why images of organization vary in their ability to comprehend organizations in dialectical and paradoxical ways.
\end{abstract}

\section{Keywords}

flux image, metaphors, metonymies, organization theory, process-entity paradox, process of imagination 


\section{IMAGINING ORGANIZATION THROUGH METAPHOR AND METONYMY: UNPACKING THE PROCESS-ENTITY PARADOX}

In the field of organization studies, Morgan's seminal book 'Images of Organization' (1986) has laid the groundwork for an entire research tradition of studying organizational phenomena through metaphorical lenses (see, for instance, Oswick et al., 2004; Putnam et al., 1996; Tsoukas, 1991, 1993; Weick, 1989). A metaphorical lens is generally defined as a way of referring to and thinking of one term or concept (the target) in terms of another (the source), with the latter stemming from a domain of knowledge and language use that is not typically associated with the target (Cornelissen, 2005; Morgan, 1983; Oswick et al., 2002; Tsoukas, 1991). The force of Morgan's eight images (e.g., organization as organism, brain, or machine) lies in their ability to inspire creative analogical reasoning that allows us to perceive organizational phenomena (the target) in light of neighboring conceptual domains (the source).

Within Morgan's (1986) canonical list of images, one of them stands out in particular: that of the 'organization as flux and transformation' (hereafter, the 'flux image'). This image is special in two regards. First, while most of Morgan's images tend to establish an entity-entity relation by metaphorically comparing the organization, as an entity, to yet another entity (e.g., an organization is like an organism, a brain, or a machine), the flux image establishes an entityprocess relation. At the same time, it invites scholars to understand organizations in a paradoxical way (Poole and Van de Ven, 1989; Smith and Lewis, 2011) by drawing a relation between the objectified notion of an organization (an entity) and a process (a non-entity). Since Morgan's (1986) initial writings, the process-entity paradox in understanding organizational phenomena remains unsettled (see Demir and Lychnell, 2015). Weick (2004: 411) summarizes the situation by saying that while 'researchers already have reasonable control of conceptual 
images that depict more stable, crystal-like texts, $[\ldots]$ the problem is that we have less control over images that capture dynamics and flux' (p. 411). Yet, as he had also mentioned in his earlier writings, '[i]t is the very fact that processes elude both researchers and managers that makes it more important for us to suggest ways in which people can gain at least intellectual control over this property of organizations' (Weick, 1979: 43).

Second, the flux image differs from Morgan's (1986) other images in that it can be seen not only as a metaphor, but also as a metonymy, its close sibling within the larger family of rhetorical tropes (see Morgan, 1996: 231). Metonymies are generally defined as 'figures of speech in which one expression is used to refer to the standard referent of a related one' (Cornelissen, 2008: 82). The analogical reasoning of metonymy typically establishes a partwhole substitution (pars pro toto). As Manning (1979: 662) writes: 'Metonymy takes the whole (an organization) to be indicated by its parts (e.g., the number of levels in an organization [...]). The whole is thus represented by the parts; the essential features of a whole are reduced to indices.' We argue that compared to the other images that Morgan (1986) developed, the flux image is special in that it follows a different form of thinking. In considering how single instances or processes can be indicative of a larger entity, it strongly combines metaphorical and metonymic reasoning. In doing so, the flux image invites us to understand organizations as consisting of, and being constituted by, processes of flux and transformation.

In this paper, we follow the call by Hernes and Weik (2007a: 253) to further 'illuminate the subtleties' of the 'process-entity paradox.' Tackling the process-entity paradox is important considering that, as Chia argued, organizational scholarship tends to privilege an 'entitative' over a 'processual' conception of reality (2005: 115), thus neglecting the inherently dynamic character of organizations (see also Tsoukas and Chia, 2002). Moreover, as Morgan (1986) 
emphasized, how we imagine an organization (either as an entity, a process, or both) makes a significant difference for the scholarly understanding and the practical management of organizations. In other words, the choice of any particular metaphor involves a process of 'seeing as,' which grounds our understanding of organizations and excludes alternative interpretations and actions (see also Cornelissen, 2005). In line with these considerations, we posit that it makes a difference for the process of imagining organization to what extent an image invites for combined metaphorical and metonymic reasoning (see also Morgan, 1996). More specifically, we argue that the more closely an image's metaphorical and metonymic dimensions are interconnected, the better the image is equipped to embrace tensions, dialectics, or paradoxical understandings of organization (such as the process-entity paradox).

Accordingly, and following Morgan's (1986) analytical strategy, we explore three offsprings of the flux image that share an analytical focus and common ground, but differ in their explanation of how processes produce organizations: 'organization as becoming' (OaB; e.g., Chia, 2005; Clegg et al., 2005; Tsoukas and Chia, 2002), 'organization as practice' (OaP; e.g., Chia and MacKay, 2007; Schatzki, 2005, 2006), and 'organization as communication' (OaC; e.g., Cooren and Taylor, 1997; McPhee and Zaug, 2000; Nicotera, 2013). These three images lend themselves particularly well to our inquiry as they all foreground a processual understanding of organizational phenomena while dealing with the entitative character of organization. Drawing out the ways in which each of these images deal with the process-entity paradox, we discuss their implications for understanding processes of imagining organization.

Our paper offers two main contributions. First, we add to Morgan's $(1986,1996)$ initial research agenda by further advancing our understanding of the process of imagining organization (see also Weick, 1989). We highlight that, in the process of imagining organization, metonymy is 
a prime activity that needs to be seen in close connection to metaphors (see also Morgan, 1996). Accordingly, we propose an analytical grid which allows for cross-comparing images of

organization regarding (1) their inherent metaphor-metonymy dynamics, (2) the (bi)directionality of the process of imagination, and (3) the degree of concreteness of the resulting figure. Importantly, we argue that this grid is useful for analyzing images of organization in comparative form as it can help explain why some images are better equipped than others to imagine organizations in paradoxical or dialectical terms (see Smith and Lewis, 2011; Putnam, 2013). Second, by applying our analytical grid, we contribute to one particular debate in organization theory (that is closely linked to Morgan's image, 1986, of the 'organization as flux'): how is it possible to imagine organization, paradoxically, as both entity and process (see Bakken and Hernes, 2006; Hernes and Weik, 2007a). Our comparative study of three different process-based images sheds light on this issue by demonstrating that the strongly the metaphorical and metonymic dimensions of an image are intertwined, the better the image's ability to keep the process-entity paradox in a fruitful tension.

\section{Connecting metaphor and metonymy}

In this paper, we move beyond a metaphorical analysis by showing the usefulness of looking at the close connection and interplay of metaphors and metonymies. Morgan (1996: 231) himself already highlighted the importance of this shift in his later writings on the topic: 'Metaphor and metonymy are always interconnected. You cannot have one without the other.' While Morgan argued that 'a metaphorical image relies on some kind of metonymic reduction, otherwise it remains thin air' (1996: 231), he also suggested that 'metonymy is entirely dependent on metaphor, for without a prefiguring image we have nothing to see' (1996: 231). This assertion corresponds with Jakobson's argument (1956/1990) that metaphors and metonymies provide the 
'bipolar structure' of language; both are necessary for the development of discourse and meaning through statements of similarity (metaphor) and contiguity (metonymy), and both mutually implicate each other in actual instances of language use (see also Eco, 1979; Lodge, 1977). However, in management and organization studies, this line of thinking has not been developed in any great detail (for some exceptions see Cornelissen, 2008; Musson and Tietze, 2004; Oswick et al., 2004; Riad and Vaara, 2011; Sillince and Barker, 2011; Spence and Thomson, 2009). Furthermore, metonymy has received little attention, even in language-inspired work in organization studies (Cornelissen, 2008; Oswick et al., 2004).

Following Morgan's call (1996), we present a new way of seeing the interrelations between metaphors and metonymies. We do so by drawing on a linguistic approach to metaphor and metonymy and their interconnections. Specifically, we suggest an analytical grid that allows us to distinguish between metaphorical and metonymic reasonings and see how specific types of combinations open up various processes of imagination.

\section{INSERT TABLE 1 ABOUT HERE}

Table 1 summarizes the three dimensions of our analytical grid to study the metaphormetonymy relations of an image: (1) the type of metaphor-metonymy dynamics, (2) the directionality of the process of imagination, and (3) the degree of concreteness of the resulting figure. In the following, we will present each of these dimensions in more detail.

Type of metaphor-metonymy dynamics 
Our framework is based on the acknowledgement that a metaphor typically crosses conventional categories of understanding (Cornelissen, 2005) and draws analogies across socially familiar registers of language and categories of knowledge. Metaphors also typically combine entire 'packages' of knowledge (Oswick et al., 2004) and thus involve a lateral, or horizontal, comparison between two concepts or terms from domains that are (at least initially) seen as distant from one another. In contrast, metonymies rely on an exchange between parts within the same domain of language use and knowledge. They involve a vertical, or contiguous, mapping between parts and elements of an entire category of thought. As previously mentioned, this exchange typically involves a part-whole substitution.

Building on these definitions, scholars from linguistics have argued that the predominant connection between metaphor and metonymy is one in which metonymy relies upon metaphor and thus should be seen as a subclass of it (e.g., Lakoff and Johnson, 1980; Searle, 1979). This understanding comes close to Morgan's (1996) initial ideas about metonymy being part of a larger metaphor and supplying the broader metaphorical image with specific details or parts (such as tasks or procedures being parts of a larger 'machine' image). Goossens $(1990,1995 \mathrm{a}$, 1995b) labeled this connection metonymy within metaphor, which occurs when 'a metonymically used entity is embedded within a (complex) metaphorical expression' (Goossens, 1995a: 172). For instance, Morgan's (1986) metaphors of 'machine,' 'organism,' or 'brain' are first based in a horizontal development of meaning: the projection of a broader metaphor is the primary heuristic for thinking about organizations. The imagination process moves here from a static metaphor to metonymic details, which are treated as simple implications or 'metaphorical entailments' (Lakoff and Johnson, 1980) that provide necessary detail and hold the broader image together 
(e.g., humans are the 'cogs' of the machine; information is the 'link' between the organism and its environment).

Another relation between metaphor and metonymy involves a metaphor from metonymy (Deignan, 2005; Deignan and Potter, 2004; Goossens, 1990, 1995a, 1995b). In this relation, an expression or thought initially develops a meaning vertically through metonymy. This meaning is then metaphorically mapped onto another domain or cues a further metaphorical interpretation. An example of this relation is the idea of an organization as an institutional actor (King et al., 2010), which presupposes a metonymy wherein separate actions, materials, and actors are compressed into one entity, which is then metaphorically understood as a single acting agent. In turn, this leads us to see the whole (the organization) as directly implied in any specific activities or parts (e.g., a corporate advertisement or an executive decision), as 'identity referents' (Whetten, 2006).

\section{INSERT FIGURE 1 ABOUT HERE}

The two types of dynamics between metaphor and metonymy are depicted in Figure 1. Metaphor involves a horizontal axis of similarity across domains of language use and knowledge. In contrast, metonymy involves only one category of thought because the connection between two phenomena is made within the same domain and so involves a vertical axis of contiguity. Together, the two axes suggest that the heuristics we use to study and understand organizations differ fundamentally, depending on whether we follow a 'metonymy within metaphor' or a 'metaphor from metonymy' dynamic. In this paper, we aim to advance our understanding of the 
role of metonymy alongside metaphor in general, and also underscore the significant potential of the 'metaphor from metonymy' route. This route has been relatively neglected, with most work in management and organization studies repeating the classic notion, found in philosophy and linguistics, that metaphor is the master trope while metonymy is a secondary figure (Green et al., 2010; Sillince and Barker, 2011).

We argue that the 'metaphor from metonymy' heuristic has great potential for organization studies, as it requires us to think of organizations in contiguous and unitary ways as something of a particular kind - before making any metaphorical leaps in our thinking. A good example is Morgan's (1986) discussion of organization as 'flux and transformation.' Morgan first operates metonymically by highlighting the importance of focusing on detailed interactions and changing patterns of organizational behavior that implicate larger structures and concepts such as 'organization,' 'environment,' and 'society.' He then refers to a wide range of writings, from complexity science and self-organizing systems to ecology, that, as metaphorical ways of thinking, present possible means of finding patterns of causality and emergent effects. Importantly, these ways of thinking only flow from the initial metonymic focus on specific 'patterns' of action and interaction.

Another related advantage of the 'metaphor from metonymy' route is that it enables an analysis of the changing and unfolding process of organization (or organizing) by focusing on how parts and the whole interrelate - and thus on how organization (as an abstract, macro concept) is at the same time present, or implicated, in specific actions, communications, bundles of resources, or any other particular set of details on the ground (i.e., on the micro level). This recursive way of thinking about how the entity and process of organization are implicated in one another is a particularly insightful heuristic for process research in organization studies. 


\section{Directionality of the process of imagination}

Besides focusing on the relationship between metaphors and metonymies, we also propose to consider the directionality of the process of imagination in the metaphorical (i.e. horizontal) and metonymic (i.e. vertical) dimension. Wee (2005) emphasizes that rhetorical figures such as metaphors do not necessarily represent a 'one-way street' from the source to the target domain (p. 367). Thus, he proposes to look at the degree to which an image allows for bidirectionality, that is, the dynamic process of recursive and mutual recontextualization between the source and target domains. Wee (2005) links the bidirectionality of an image closely to its heuristic value. Vivid images tend to establish a 'dynamic [bidirectional] link between the source and target domains, through which the contextual complexity of one domain can be made available to the other in the form of a coevolutionary process' (Schoeneborn et al., 2013: 438). Accordingly, within each dimension of our grid (i.e. horizontal or vertical), we can distinguish to what extent an image invites for unidirectional (one-way) and bidirectional (two-way) processes of imagination. For instance, a bidirectional relation in the metaphorical (horizontal) dimension is established as soon as one imagines the target domain (e.g., organization) not only in the light of a source domain (e.g., the human brain) but also the other way around (as shown by the dotted horizontal arrow in Figure 2). When this happens, an image allows for setting up chains of (backand-forth) associations (Putnam and Boys, 2006) between the source and the target domains that allow for building a richer and more dynamic picture of both domains (e.g., by understanding organizations in terms of the human brain and, vice versa, by understanding the human brain in terms of organization; see Morgan, 1986; Spender, 1996).

In the metonymic (vertical) dimension, a bidirectional relation is established as soon as an image invites not only for comprehending the constitutive elements as representative of the 
whole (pars pro toto) but also the other way around (totum pro parte; as shown by the dotted vertical arrow in Figure 2). For instance, we can also consider the image of the 'organization as brain' (Morgan, 1986) as a metonymy, given that it invites not only for imagining organizations metaphorically as brains but also as consisting of brains as its constitutive elements.

Bidirectionality in the vertical (metonymic) dimension is established if the 'metonymic compression' (Cornelissen, 20006) works both ways: for instance, the 'organization as brain' image allows for comprehending one specific 'mastermind' as the representation of the organization (e.g., Steve Jobs as 'the' incarnation of Apple) - or, vice versa, for comprehending the organization as one 'collective mind' where the system of interrelated actions stands in for the individual human actors involved (e.g., the study by Weick and Robert, 1993, on flight operations on an aircraft carrier deck as a form of collective mind).

\section{INSERT FIGURE 2 ABOUT HERE}

\section{Concreteness of the resulting figure}

In addition to the type of metaphor-metonymy dynamics and the directionality of the process of imagination, we propose analyzing a third aspect of images of organization: their degree of concreteness. An effective metaphor is often described as one in which an abstract target is represented through a more concrete, more detailed, and more easily understood source, such as imagining an organization as a machine (Tsoukas, 1991: 566). Similarly, metonymy works by making an abstract and larger phenomenon be understood through the more particular and concrete (i.e. understanding an abstract whole through its more concrete constitutive parts). The 
concrete nature of a metaphor or metonymy is an important aspect of images of organization in that it influences whether the resulting image will be easily understood. In this respect, entitative images such as the 'organization as machine' metaphor are likely to present a greater degree of concreteness than processual images, such as the 'flux image,' because of their capacity to convey an objective representation. We see the degree of concreteness as a particular challenge for dynamic and processual images of organization, which, as we will develop next, tend to be more abstract due to the philosophical and ontological stances on which they rely.

In the next section, we will mobilize our analytical grid to question the above-mentioned three offsprings of the flux image ('organization as becoming,' 'organization as practice,' and 'organization as communication') and explain why and how these three images differ in their ability to tackle the process-entity paradox of organization.

\section{The metaphor-metonymy relation in three offsprings of the flux image}

We now have the basis for returning to Morgan's (1986) image of the 'organization as flux and transformation.' For Morgan, exploring the flux image is relevant to studying and managing organizations, as it invites researchers and practitioners to search 'for the dynamics that generate and sustain organizations and their environments as concrete social forms' (1986: 235) - a focus not developed in the other images of his canonical list. Consequently, he calls for studying organizational life through a close examination of 'deep processes of transformation and change.'

Morgan's starting point in discussing the flux image is the acknowledgement that organizations as entities are transformed by the inherent processes that constitute them. This 
argument is consistent with what Hernes and Weik (2007a) call endogenous process views, in which processes are considered to be 'actions which form entities' (Bakken and Hernes, 2006: 1604). Over the past decades, scholars in organization theory have shown a growing interest in such processual notions of organization. Some of these views can be seen as offsprings of Morgan's (1986) image of 'organization as flux and transformation.' Most prominently, vivid streams of research have lately emerged under the larger umbrella of 'process organization studies' (for a recent overview, see Langley et al., 2013).

From the various perspectives on process found in contemporary organization studies, we focus on three theoretical streams in particular. Each of these streams is guided by a specific image. First, inspired by fundamental process ontologies (e.g., Rescher, 2000), organizational scholars have proposed the image of the organization as becoming (Chia, 1995, 2005; Clegg et al., 2005; Tsoukas and Chia, 2002). The image of becoming (as opposed to being; see Demir and Lychnell, 2015) implies that organizations are ongoing and ever-changing endeavors (Tsoukas and Chia, 2002). Second, a closely related stream of theorizing is grounded in the image of organization as practice (Chia and MacKay, 2007; Nicolini, 2013). In the most explicit variant of a practice ontology of organizations, Schatzki $(2005,2006)$ suggests grasping organizations as bundles of interrelated practices and material arrangements. Third, scholars from the transdisciplinary field of organizational communication studies have mobilized the image of organization as communication (Cooren et al., 2011; Luhmann, 2003; McPhee and Zaug, 2000; Taylor and Van Every, 2000). The term 'communication' refers here to a specific type of practice, a complex and dynamic process of (symbolic and material) meaning negotiation that is fundamental to organizational existence (Ashcraft et al., 2009: 22). 
We concentrate on these three images in particular because they each subscribe to an endogenous understanding of the process-entity relation (Hernes and Weik, 2007a). Furthermore, all three images entail strong linkages of the metaphorical and metonymic dimension and thus are particularly suitable for our inquiry. Finally, in contrast to other processual images of organization (e.g., path dependency theory, Sydow et al., 2009; or the evolutionary process approach, Weick and Quinn, 1999), each of the chosen images also unites a vibrant and strongly institutionalized community within contemporary organization studies (for instance, process philosophy scholars tend to take inspiration from the OaB image, e.g., Helin et al., 2014; strategy-as-practice scholars, the OaP image, e.g., Golsorkhi et al., 2010; and scholars interested in the Communicative Constitution of Organization (CCO), the OaC image, e.g., Brummans et al., 2014). In the following sections, we explore in more detail (1) how these images evoke metaphorical and metonymic forms of reasoning and their dynamic interrelations (by mobilizing the three dimensions of our analytical grid) and (2) how these different processes of imagination contribute to our understanding of the process-entity paradox.

\section{Organization as Becoming (OaB)}

Within endogenous process views on organization (Hernes and Weik, 2007a), the most fundamental reconsideration of the process-entity relation has been proposed by scholars working with the image of 'organization as becoming' (OaB) (Chia, 1995, 2005; Hernes, 2014; Hernes and Weik, 2007a, 2007b; Tsoukas and Chia, 2002). In line with more general trends in postmodern thinking, the proponents of this perspective tend to question the existence of stable entities altogether: 'What is real for postmodern thinkers are not so much social states, or entities, but emergent relational interactions and patternings that are recursively intimated in the fluxing and transforming of our life-worlds' (Chia, 1995: 581-2). Tsoukas and Chia relate these 
considerations to organizational phenomena and argue that these should not be 'treated as entities, as accomplished events, but as enactments - unfolding processes involving actors making choices interactively, in inescapably local conditions' (2002: 577).

In this section, by drawing on our analytical grid (see Table 1 above), we examine the metaphorical and metonymic dimensions of the $\mathrm{OaB}$ image and their interplay. Regarding the type of metaphor-metonymy dynamics, we argue that the metaphorical dimension dominates this image following a 'metonymy within metaphor' route. This is because the image draws a strong (horizontal) analogical comparison between two domains, inviting us to compare an organization (a supposedly concrete, stable, and fixed phenomenon) to something as fluid, loose, and ephemeral as 'becoming.' In this regard, the $\mathrm{OaB}$ image radically breaks with conventional and 'entitative' (Chia, 2005: 115) notions of organization. Accordingly, Hernes and Weik assert that 'a conceptualization of organization as becoming [...] tries to avoid the risk of turning organizations into entities' (2007b: 77).

However, the $\mathrm{OaB}$ image is also characterized by metonymic reasoning in that it presupposes part-whole relations. Proponents of the $\mathrm{OaB}$ image suggest that an organization is ultimately an 'aggregation' or 'assemblage' of unfolding processes (Chia, 1995: 597). This idea, in turn, suggests that 'organization as becoming' can actually be decomposed in its constitutive processes and activities. Accordingly, Chia asserts that, seen from an $\mathrm{OaB}$ perspective, 'the basic unit of reality is not an atom or thing but an "event-cluster" forming a relatively stable pattern of relations' (Chia, 2005: 128). One example of this metonymic reasoning is the recent ethnographic study of a South Korean credit card company by Bjerregaard and Jonasson (2014). The authors demonstrate how this firm handled contradicting institutional logics in the aftermath of the Asian economic crisis of 1997. To study the actual work practices involved in handling 
these contradicting logics, Bjerregaard and Jonasson suggest turning to 'ongoing micro-events, actions and interactions as the critical site of becoming' (2014: 1531). The OaB lens thus invites us to imagine an organization as the nexus that holds together various clusters of 'micro-events'. These clusters, in turn, provide the organization with a more stable appearance - one that can be maintained, paradoxically, even though the organization's constitutive parts (the events, activities, and processes) are presumed to be 'perpetually perishing' (Hernes, 2014: 46).We can conclude that in this view, the organization's existence is precarious in that it 'comes into being and then vanishes; it never really is, except in the imagination' (Hernes, 2014: 46).

In terms of the directionality of the process of imagination, we argue that the OaB image is mostly unidirectional in character. Scholars following this image are primarily interested in examining organizational phenomena through a 'becoming' lens. However, this image does not necessarily invite us to investigate in the opposite direction by asking what we can learn about the world's continuous becoming through an organizational lens. Nevertheless, proponents of the OaB image note some form of bidirectionality in the horizontal (metaphorical) dimension, at least by emphasizing the inherently recursive relation between organization and becoming/change. For instance, as Tsoukas and Chia assert: 'While organization aims at stemming change, it is also the outcome of change' (2002: 570). To exemplify their argument, they (2002: 572) mobilize the image of an acrobat on a high wire. They argue that she maintains her stability by 'continuously correcting her imbalances.' The beauty of her act - what makes the spectators hold their breath - is the 'illusion of stability' that she creates through movement. What is true for the acrobat, Tsoukas and Chia (2002) argue, is also true for organizations: organizational stability is the result of movement, change, and continuous imbalances. 
We also scrutinize the degree of concreteness of the $\mathrm{OaB}$ image. While the idea of organizations being in a continuous state of becoming resonates well with the experiential basis of empirical studies that emphasize the fluid and inherently precarious character of organizational phenomena (e.g., O’Mahony and Ferraro, 2007), the resulting figure ultimately remains somewhat abstract and generic. This is because the ontology of becoming is conceptualized to apply to the world as a whole and, accordingly, to many kinds of processualities, including questioning what is normally seen as an entity (see, for instance, Whitehead's idea of the mountain as process; Stengers, 2005). Hence, the OaB image leaves open what particular kinds of processes can be constitutive of organization. This is where the images of 'organization as practice' and 'organization as communication' tend to make more specific suggestions, as we will see next.

Finally, let us look at how the OaB image allows us to deal with the process-entity paradox. The OaB lens is thought-provoking because it inspires organizational scholars (and practitioners) to radically rethink and question entitative notions of organization (Chia, 1995, 2005) by addressing the paradoxical constitution of organization (that which is stable) as becoming (that which is in continuous flux; see also Tsoukas and Chia, 2002: 577). However, ultimately, the $\mathrm{OaB}$ image does not directly tackle the process-entity paradox because, in its most radical variants (e.g, Chia, 1995; Hernes and Weik, 2007b), it tends to reject the idea of 'organization as entity' altogether.

\section{Organization as Practice (OaP)}

The second stream of theorizing that we have chosen for this analysis is closely related to the previous one in that it also emphasizes processes over entities. Commonly associated with the 
'practice turn' in the social sciences (Schatzki et al., 2001), the OaP perspective highlights the situated, embodied, and unfolding character of social phenomena, 'as they become evident in the here-and-now' (Miettinen et al., 2009: 1309). In general, practices are defined as 'what people do' (e.g., Jarzabkowski, 2008) and thus may refer to all sorts of activities in the social realm, such as political, cooking, recreational, and religious practices (Schatzki, 2006: 1863-4). For our analysis, we will retain Schatzki et al.'s (2001: 11) more specific definition of practices as 'embodied, materially mediated arrays of human activity centrally organized around shared practical understanding.'

This focus on practice has developed across a number of topic areas within organization studies, such as strategizing (Vaara and Whittington, 2012), project management (Blomquist et al., 2010), or technology use (Orlikowski, 2007). Feldman and Orlikowski (2011: 1240) identified three approaches to the study of practice in organization studies: (1) the empirical approach, which focuses on 'how people act in organizational contexts,' (2) the theoretical approach, which focuses on 'the relations between the actions people take and the structures of organizational life,' and (3) the philosophical approach, which focuses on 'the constitutive role of practices in producing organizational reality.' We will retain the latter to analyze the 'organization as practice' image, as it explicitly engages in an ontological reflection about the primacy of social practices in constituting organization, and thus addresses the entity-process paradox. ${ }^{1}$ More specifically, we will focus on the work of Schatzki $(2005,2006)$, for whom the practice perspective represents a distinct social ontology - a 'site ontology' - that holds crucial implications for organizations.

Schatzki's practice ontology (Schatzki et al., 2001) is based on the belief that social phenomena occur in 'sites,' which are particular types of contexts composed of a 'nexus of 
practices' and 'material arrangements,' what he calls a 'field of practices.' Moreover, in this view, all social phenomena occur within and compose the field of practices that characterize them. This recursive relation between the field of practices and the social phenomena is a key principle of the practice lens. It implies that 'phenomena always exist in relation to each other, produced through a process of mutual constitution' (Feldman and Orlikowski, 2011: 1242). The ongoing and processual nature of this relationship suggests that social phenomena are accomplishments produced, maintained, and transformed in every instance of action. Schatzki has explicitly applied this practice ontology to organization, which he defines as 'a bundle of practices and arrangements' that includes, for example, 'executive board practices, managerial decision-making practices, communication practices between managers and employees, practices of design, construction, supervision, shop-floor activity, advertising, and upkeep, as well as dispersed practices of giving orders, asking questions, and reporting problems' (Schatzki, 2005: 477).

Regarding the metaphor-metonymy dynamic, Schatzki’s social ontology of organization gives us an interesting view of the $\mathrm{OaP}$ image as grounded in a 'metaphor from metonymy' dynamic. The notion of 'site' is particularly relevant here: an organization is said to be situated within practices. This metonymic reasoning operates as a compression (on the vertical level) wherein the distinct elements that compose practices - human activities, bodies, materiality, rules, emotions, shared understanding - are compressed into an entity (the organization). This compression takes the image of a 'bundle' of practices, or of a loosely coupled arrangement of social and material elements, which together constitute the organization. This image of the 'bundle' of practices has been applied, for instance, in the project management literature to 
highlight the need for contextualizing projects (Winter et al., 2006) and for broadening their scope to include other organizational practices (Atkinson et al., 2006).

The 'bundle' metaphor is quite different than others, such as the organizational actor metaphor (King et al., 2010) that we discussed previously, in that the specific components or parts need to be held together to act as 'identity referents' (Whetten, 2006) of the whole. In other words, the metonymic reasoning underlying Schatzki's $(2005,2006)$ version of the OaP image leads us to see the organization as implied in the relation (or mesh) of the specific elements that compose practice, and not in each one independently. Moreover, following what can be called a matryoshka logic (i.e., an 'object within similar object' or 'onion' metaphor), this metonymic reasoning allows us to understand the coupling of the 'bundle' as a continuous unfolding of the organization into practices, which are then unfolded into actions, which can also be unfolded into understandings, rules, emotions, and so forth. Bechky (2006) provides an interesting illustration of the metonymic reasoning underlying the OaP image. In her study of film projects, she shows how film work is collectively accomplished and coordinated through an array of interconnected practices. More specifically, her study establishes three key practices (enthusiastic thanking, polite admonishing, and role-oriented joking) through which film crew members learn and negotiate their roles. In other words, the system of roles in the film business is enacted and negotiated in situ through these practices.

Next, let us consider the directionality of the process of imagination. In the vertical (metonymic) dimension, following the principle of recursivity that characterizes the practice perspective (Feldman and Orlikowski, 2011), the OaP image presents a bidirectional relation between the parts and the whole. In this context, what Schatzki (2005) calls the structure or organization of practices is particularly relevant to our inquiry. In his view, practices 'organize' 
organization, but are also ‘organized' by it. Let us return to Bechky’s (2006) study on film projects to illustrate this idea. As mentioned previously, her study illuminates the very practices that constitute the system of roles in filmmaking (in a metonymic-vertical logic, from the parts to the whole). At the same time, Bechky also demonstrates how, conversely, the system of roles organizes these practices (from the whole to the parts). For example, she shows how international career paths influence role-oriented joking. She concludes that film projects are organized around structured role systems whose nuances are negotiated in practices. As this example shows, the bidirectionality of the OaP image allows for a processual understanding of organization through the recursive dynamic between practices and the structure of practice.

Regarding the degree of concreteness of the OaP image, we must note the emphasis on embodiment and materiality, which, as mentioned previously, is one of the distinctive characteristics of the OaP approach. Compared to the image of 'organization as becoming,' the notion of practice tends to be more concrete, especially when considered in its empirical variant (cooking practices, teaching practices, ordering practices, etc.). Moreover, this concreteness can also be related to the embeddedness of organization in particular sites or contexts and material events. As Schatzki (2006) notes, the happening of an organization consists of the unfolding of performances in particular sites supported by the material world. The emphasis given to the embodiment of practices results in a metaphor that appeals to the direct and experiential basis (Gibbs, 2006) of human activities, and thus to a concrete understanding of organization as experienced phenomenon. Let us take as an example Nicolini's (2009) study on telemedicine, in which he proposes to zoom into the material and situated local production of organized activity and then zoom out, by exploring the connections between each particular instance of this activity. 'Zooming in' implies describing an array of embodied practices and artifacts such as official 
documents, nurses' and physicians' narratives and conversations, and bodily actions. This first movement is crucial for representing and understanding practices, yet, as Nicolini argues, it is not enough. While staying in the realm of practices, 'zooming out' allows for following the connections between these practices in a historical account of organized activities.

To conclude, let us consider how the OaP image deals with the process-entity paradox. We argue that the strong focus on practices as the starting point of the analogical reasoning presented in this image and the metonymic compression at work diminish the entity-like dimension of organization. The metaphors implied in the ideas of organization as 'site,' 'field,' or 'bundle' of practices result in a loosely coupled, yet grounded, entity expressed in an array of human activities. Scaling up from the parts to the whole is rather difficult: the organization stays at the level of human action or enacted structures (e.g., a system of roles). However, this does not imply a static definition of organization. To the contrary, the continuous unfolding of organization into actions, and then into practices, rules, emotions, matters, and so forth, offers a strong processual image.

\section{Organization as Communication (OaC)}

The third image we analyze, the 'organization as communication' $(\mathrm{OaC})$ image, has in the last decade gained considerable traction in organization studies, and particularly in organizational communication studies. Anchored in a 'communicative constitution of organization' or 'CCO' perspective (for a recent overview, see Brummans et al., 2014), this stream of theorizing is held together by the core idea that organizations essentially 'consist of,' 'emerge in,' or 'are constituted by' communication (Kuhn, 2012; Putnam and Nicotera, 2009; Taylor and Van Every, 2000). The $\mathrm{OaC}$ image is based on the assumption that language does not merely serve 
representational purposes but creates, constitutes, and shapes instances of social reality (Cooren, 2012; Craig, 1999). Accordingly, the phenomenon of organization is imagined here as a communication-based entity (Taylor and Cooren, 1997), consisting primarily of communicational events or processes. It follows that individual organizational membership, hierarchies, job roles, etc., are seen as secondary means to make these occurrences of communication more likely (Blaschke et al., 2012).

Generally speaking, the main proponents of the $\mathrm{OaC}$ perspective are in close alignment with endogenous process thinking (e.g., Hernes and Weik, 2007a), based on the assumption that organizations do not predate the very processes (of communication) that give rise to their existence in the first place. However, compared to the $\mathrm{OaB}$ image, the $\mathrm{OaC}$ image is slightly more specific in that only communication (as a process of meaning negotiation through symbolic and material use; Ashcraft et al., 2009) is seen as the fundamental constitutive process able to incarnate organizations. In other words, communication (the part) is grasped as the site and surface where the organization (the whole) gets instantiated and thus can sustain its existence (Taylor and Van Every, 2000). Moreover, a distinctive feature of the $\mathrm{OaC}$ image is that it presents a symmetrical or equivalent (e.g., Fairhurst and Putnam, 1999) relation between communication and organization: both terms are considered as 'variant expressions for the same reality' (Taylor et al., 1996: 28). We argue that this equivalent relation avoids the trap of considering organization (the whole) as a primary and separate phenomenon from its (constitutive) parts. Consequently, this process of imagination opens up paradoxical and recursive paths of thinking about organizations. To further understand how the OaC image unfolds this constitutive logic, we will apply our analytical grid especially to the works of one of the core schools of CCO thinking, the Montreal School (see Brummans et al., 2014), which has 
developed a rich communicational ontology of organization and organizing over the past twenty years.

Concerning the type of the metonymy-metaphor dynamic, we can classify the $\mathrm{OaC}$ image as a 'metaphor from metonymy' relation. In the Montreal School's conceptualization of organization, the starting point is a form of metonymic reasoning: 'When I imagine an organization I have in mind nothing more than an interlocking network of communication processes' (Taylor, 2003: 12). In other words, Taylor and his followers essentially rely on the idea that the organization consists of events or processes of communication (conversations and texts) that are connected to each other. The underlying metonymic logic that characterizes this school's mode of thinking is to 'explain the large [organization] by looking at the small [communication]' (Bencherki and Cooren, 2011: 1585). However, while the metonymic OaC image serves as the baseline premise of the Montreal School's work, its proponents have mobilized additional metaphors in order to illuminate how the organization as an entity is connected to its constitutive parts, that is, events or processes of communication.

For instance, Bencherki and Cooren (2011) suggest explaining the constitutive relation between organization and communication by drawing on the metaphorical domain of ownership or possession through terms like 'attribution' (the process of acknowledging or ascribing ownership) or 'appropriation' (the process of acquiring or claiming ownership). In their view, the organization as entity comes into being through both attributive and possessive relations to the communicative processes that represent its constitutive parts. Accordingly, the constitution of organization requires (1) the continuous and interrelated occurrence of communicative processes or events that are attributed to the organization as a collective entity or actor (Taylor and Cooren, 1997) and (2) that the organization is constructed as an entity that starts 'possessing' the very 
communicative processes that have given rise to its existence in the first place (Bencherki and Cooren, 2011).

In terms of the directionality of the process of imagination, the metonymic compression of the $\mathrm{OaC}$ image results in a symmetry and bidirectionality between the whole-parts relationship in both the vertical and horizontal axes. In the vertical (metonymic) dimension, the organization is imagined as being constituted through the occurrence of communicational events, which can also be seen as being populated and constituted by various 'figures,' one of which is the organization (Cooren, 2010). Interestingly, this bidirectionality also applies to the horizontal (metaphorical)s dimension of the $\mathrm{OaC}$ image: one can either perceive the organization or organizing as being 'like' communication or, conversely, perceive that communication has organizing properties (Cooren, 2000). Robichaud and Cooren (referring to the work of James R. Taylor) also point out this recursive relation by defining organization as 'an ongoing flux of interaction from which stabilized patterns of relations and meanings emerge, which, in turn, feed back into the interactions and joint activities of organizational members' (2013: xvi). In other words, the OaC image evokes to grasp organization in a bidirectional vertical (metonymic) relation.

Concerning the degree of concreteness of the resulting figure, we must note two ideas related to this communicational lens. The first one relates to the empirical approach that characterizes CCO scholarship, which is summarized in the following motto: 'never leav[e] the realm of communicational events' (Cooren et al., 2011: 1153). A communicational event can be understood as an interactional event, which is not limited to humans interacting with each other but also includes talk, discourse, artifacts, metaphors, architectural elements, bodies, texts, or narratives in their performative character. Moreover, an event is not a single episode of action: it is an ongoing chain of interactions. This focus on communicational events results in what 
Fairhurst and Putnam (2004: 6) call a 'grounded in action' approach, which puts forward the contingent and situated dimensions of meaning negotiation that constitute organizational realities. A recent example is Vasquez et al.'s (forthcoming) article on the (dis)ordering properties of organizational text in the context of project organizing. This empirical study focuses on three communicational events taken from three distinct project organizing contexts to examine the dynamics of delineating meaning (ordering) and opening meaning (disordering) that were at play in what is called in the article texts-in-use (e.g., a proposal form, a working document, and a post-project report in PowerPoint). The focus on communicational events allows the analysis to be grounded in situated local practices. However, the argumentation is also linked to a processual understanding of organization by viewing project organizations as being 'moved by' and 'consisting of' communicative practices of ordering and disordering.

The second idea concerns the material dimension of organization. Through the CCO lens, and according to the Montreal School, for the organization to exist it must be materialized in talk, bodies, objects, sites, texts, and so forth. Hence, these materializations are seen as acting for, or speaking on behalf of, the organization. They are considered to be actors that take part in constituting the organizational reality. Cooren et al. (2011: 1153) give the following example: 'Something as material and (apparently) inert as a building, for instance, participates in the constitution of an organization through what it does: sheltering operations, channeling activities, impressing visitors, communicating some specific values, norms, and ideologies.'

Finally, let us consider how the $\mathrm{OaC}$ image enables scholars to tackle the process-entity paradox. The $\mathrm{OaC}$ image not only invites us to perceive the organization-communication relation in the form of a metonymic compression linking the whole to its parts but, importantly, the image also provides us with specific answers to the question of how the parts (communication) 
constitute the whole (organization). In other words, how is the organization as a somewhat stable entity constituted by something as fluid and dynamic as communication processes? The answer to this question lies in the double role of communication. First, it is in and through communication that meaning is constructed and that an interpretive framework is created to make sense of organizational situations (process). Second, communication transforms these scattered situations and local initiatives into a collective actor (entity). Thus, the paradoxical relation between entity and process that characterizes process thinking (Hernes and Weik, 2007a) is addressed by suggesting that organizations, as whole entities, are constantly reproduced in ongoing processes of communication. CCO scholars thus attend to both process and entity, as well as organization and organizing (Cooren et al., 2011).

\section{Discussion}

We are finally ready to compare the three offsprings of the flux image - organization as becoming $(\mathrm{OaB})$, organization as practice $(\mathrm{OaP})$, and organization as communication $(\mathrm{OaC})$ - by drawing on the three dimensions of our analytical framework: (1) the nature of the metaphormetonymy dynamics, (2) the directionality of the process of imagination, and (3) the degree of concreteness of the resulting figure. Ultimately, these three dimensions can also serve as a means to explain the varying degrees to which these images allow for tackling the process-entity paradox. Table 2 summarizes the key elements of comparison between the three images that we have identified, based on our analytical framework. In the following, we will further illuminate these elements by discussing them point by point. 


\section{INSERT TABLE 2 ABOUT HERE}

(1) Metaphor-metonymy dynamics. The metaphor-metonymy dynamics play out differently for each of the three images. As discussed above, the $\mathrm{OaB}$ image seems to be primarily driven by a metaphorical impetus, effectively challenging conventional notions of organization by means of the 'becoming' analogy (Tsoukas and Chia, 2002). Hence, we can argue that the OaB image represents 'metonymy within metaphor' (Goossens, 1990), given that the metonymic idea that organizations consist of processes of becoming is less pronounced. For instance, even though Tsoukas and Chia (2002) conceptualize organization as being generated and constituted by perpetual change or 'becoming,' they also describe organization as an emergent order distinct from the very processes that have produced it in the first place. Our assessment is that, in the case of the $\mathrm{OaB}$ image, the process of imagination is primarily driven by metaphorical or horizontal logic. This is confirmed by the observation that scholars centered around the OaB image (who would affiliate themselves with 'process organization studies' or 'process philosophy') tend to reproduce this horizontal logic by moving from one process analogy to the next in their theorizations of organization (e.g., in the various chapters of the process philosophy handbook by Helin et al., 2014). However, this mode of reasoning may prevent scholars from delving deeper into the metonymic dimension of the image, which requires to more clearly specify the parts or processes that constitute organization.

In contrast, the process of imagination is different in the case of the $\mathrm{OaP}$ and $\mathrm{OaC}$ images, which are both more strongly driven by a metonymic logic. The key is to look, at the micro level, at practices as arrays of activities (Schatzki, 2005, 2006) and/or communicative interactions 
(Bencherki and Cooren, 2011; Cooren et al., 2011) that collectively constitute organization. Accordingly, we believe it is valid to classify these two images as 'metaphors from metonymy' (Goossens, 1990), given that the metonymic insight is primary, and the metaphorical insight, secondary.

(2) Directionality of the imagination of process. In this dimension, we are interested in the extent to which the images invite for bidirectional thinking. As specified in our analytical grid (see Table 1 and Figure 2 above), we distinguish between bidirectionality in the horizontal (metaphorical) and vertical (metonymic) dimension. In the horizontal dimension, both the OaB and $\mathrm{OaP}$ images establish an asymmetric relation between the source and target domains. In both cases, the process of imagination follows a unidirectional logic from the source to the target in that the becoming (or the practice) lens sheds light on organizational phenomena. However, this logic does not necessarily work the other way around. For instance, one can hardly find $\mathrm{OaB}$ scholars interested in how an organizational lens can advance our understanding of becoming, which is a rather vague domain to begin with. In contrast, the $\mathrm{OaC}$ image seems to apply more symmetry and bidirectionality. While a large body of OaC-inspired research is concerned with viewing organizations through a communication-centered lens (thus operating in a similar logic to the $\mathrm{OaB}$ and $\mathrm{OaP}$ images), we can also find works in the same perspective that examine, in the opposite direction, the organizing properties of communication (e.g., Cooren, 2000; Vasquez et al., forthcoming). Accordingly, we can conclude that the OaC image is special in that it sparks bidirectional thinking in the horizontal dimension more than the other offsprings of the flux image. The bidirectionality of the $\mathrm{OaC}$ image even goes as far as to metaphorically connect entire academic disciplines (organization studies and communication studies) in a symmetric and isomorphic way: 'If, indeed, the two constructs [organization and communication] are 
isomorphic, then all organizational theories contain implicit notions about communication and all communication theories, in turn, provide important insights about organizing' (Putnam et al., 1996: 396).

In the vertical dimension, however, bidirectionality plays out in different ways. To describe these differences in more detail, we draw on the analytical terminology established by Smith (1993; see also Putnam et al., 1996). Smith argued that the organization-process relation ${ }^{2}$ can be described in various terms that exhibit different degrees of bidirectionality and symmetry. For her, the two strongest forms of bidirectionality are (1) 'coproduction' (i.e., organizations and their processes 'stand in a coproductive relation as producers/products of one another'; Smith, 1993: 11) and (2) 'equivalence' (i.e., organizations and their processes become one and the same). By drawing on her terminology to describe the vertical directionality of the three images, we can characterize the $\mathrm{OaB}$ image (in the version of Tsoukas and Chia, 2002) as bidirectional in the sense of 'coproduction.' As emphasized above, the OaB image is distinguished by an underlying logic according to which processes (becoming) produce organization (order), which produces processes, which in turn coproduce organization, and so on. However, in this regard, the $\mathrm{OaB}$ image does not go as far as the $\mathrm{OaP}$ and $\mathrm{OaC}$ images, which extend vertical bidirectionality between an entity and its constitutive parts or processes toward 'equivalence.' In other words, the $\mathrm{OaP}$ and $\mathrm{OaC}$ images both imply that the organization becomes inseparable from its constitutive processes (i.e. practices or communication).

(3) Degree of concreteness of the resulting figure. The criterion of concreteness is based on the assumption that metaphors and metonymies tend to become powerful heuristic devices by illuminating a target domain in the light of a more concrete and comprehensible source domain (see Cornelissen, 2008; Tsoukas, 1991). As we can see in Table 2, the concreteness of the 
resulting figure in the three images again plays out differently. The OaB image invites us to draw on a rather abstract source domain (becoming) so as to shed light on a similarly abstract target domain (organization). Consequently, the image results in a rather generic figure, difficult to grasp empirically. In contrast, the $\mathrm{OaP}$ and $\mathrm{OaC}$ images, presumably due to their stronger emphasis on metonymic reasoning, offer more concrete and observable figures. More than the $\mathrm{OaB}$ image, the $\mathrm{OaP}$ and $\mathrm{OaC}$ images invite scholars to ground their understanding of organizations in the study of empirically observable practices (as arrays of actual activities; Schatzki et al., 2001) and communication (as interplay of conversations and texts; Taylor and Van Every, 2000). Both images are grounded in embodied (and very material) source domains, thus facilitating the heuristic value of the process of imagination.

Furthermore, the $\mathrm{OaP}$ and $\mathrm{OaC}$ images differ in the degree of concreteness of the target domain. The resulting figure of the $\mathrm{OaC}$ image tends to be more concrete than that of the $\mathrm{OaP}$ image. As previously argued, the OaP image invites us to perceive organizations as 'bundles,' 'sites,' or 'fields' of practices. The resulting figure invokes a somewhat abstract process of imagination that is limited in fostering our understanding of organizations as (processual) entities (see King et al., 2010). In contrast, the degree of concreteness of the resulting figure tends to be higher in the $\mathrm{OaC}$ image. This is primarily because of the actorhood metaphor that this image entails. Personifying the organization as a 'macro-actor' (Robichaud et al., 2004) grounds the target domain in an experiential basis, which contributes to making the $\mathrm{OaC}$ image more concrete. However, one can argue that the anthropomorphization of organizations as actors (see Shepherd and Sutcliffe, 2015) may result in a too reified and entitative conceptualization of organizations, while neglecting the processual side. 
In sum, we can classify the three images in a continuum that ranges from the more abstract $(\mathrm{OaB})$ to the more concrete $(\mathrm{OaC})$ imagination of organizations as processual entities. We believe that the greater degree of concreteness of the $\mathrm{OaC}$ image is due to the strength of the metonymic compression that is characteristic of this image, which helps ground the target domain of organizations in a more concrete source of domain of (empirically observable) events of communication. Interestingly, the $\mathrm{OaC}$ image can resolve some of the heuristic problems that we have pointed out in the $\mathrm{OaB}$ and $\mathrm{OaP}$ images, such as the difficulty to scale down from the whole to the parts $(\mathrm{OaB})$, and inversely, to scale up from the parts to the whole (OaP).

Type of dialectical thinking. The three dimensions of our analytical framework explored the differences in the interplay of metaphorical and metonymic reasoning in the three offsprings of Morgan's flux image (OaB, OaP, and $\mathrm{OaC})$. In the next step of our inquiry, we will share our thoughts on the metaphor-metonymy relations found in these offsprings to explain how they tackle the process-entity paradox. In order to do so, we follow Putnam's (2013) classification of dialectical approaches, which allows us to describe how each of these offspring images deals with oppositional tensions (between process and entity) in imagining organization. As we see in Table 2, the type of dialectical thinking differs in each image.

The OaB image follows a selection approach (Putnam, 2013), which entails favoring one pole of the dichotomy (process) while ignoring the opposite (entity). This approach is one of the most typical ways of addressing oppositions and contradictions. However, as mentioned by Putnam (2013), it tends to overspecialize theory building by disregarding key elements and the relationships between them. The denial of the opposite pole makes it difficult to unpack the paradox. As mentioned previously, by selecting process over entity, the OaB image falls short in providing answers to the question of how organizations are constituted by processes. 
Next, let us consider the OaP image ${ }^{3}$ that we classify as operating in a separation approach (Putnam, 2013), which is characterized by recognizing both poles of an opposition, but on different levels, at different times, or as different topics. A classic example in organization studies is the separation of micro and macro levels of analysis (see Burrell and Morgan, 1979). Usually, the macro orientations to organization engage in separation by treating the organization as a large and distinct body, dominating local interactions. In contrast, those who favor the local and adopt micro approaches (such as the OaP image) tend to engage in separation by collapsing the macro into the micro (e.g., the matryoshka logic of Schatzki's article, 2005), or by moving from one pole to the other (e.g., the focus on practices through entitative analytical constructs in the theoretical variant of the OaP image; e.g., Feldman and Orlikowski, 2011).

While the $\mathrm{OaP}$ and $\mathrm{OaC}$ images share a micro focus on social phenomena, the situation of the $\mathrm{OaC}$ image tends to be more complex and follows what Putnam (2013:27) calls a connection approach, which 'embraces the oppositions, respects and privileges both of them, preserves and celebrates their tensions to generate new constructs.' This image presents a dialogical logic in which the opposite poles are connected. Concepts such as imbrication (Taylor, 2011), coorientation (Taylor and Van Every, 2000), metaconversation (Robichaud et al., 2004), or presentification (Cooren et al., 2008) embrace the process-entity tension and work from it instead of collapsing one pole into another, or privileging one over the other. The OaC image embraces this paradox and makes it the basis of theory building: to study both the entity and the process of organization (Cooren et al., 2011). This results in a way of imagining organization in which the process-entity paradox is unpacked through a dialogical lens that teases out an array of other tensions such as presence-absence, integration-differentiation, stability-change, or fleeting- 
enduring (Putnam, 2013). Moreover, it allows for reconciling 'entitative' views of organization with processual views.

\section{Conclusion}

\section{Theoretical contributions}

Overall, we believe that our paper makes two main theoretical contributions. First, we contribute to the body of work on images of organization initiated by Morgan $(1980,1983,1986)$. In particular, our paper extends Morgan's writings by specifying the process of imagining organization through the combination of metaphorical and metonymic analysis. In his later writings, Morgan (1996) hinted at the importance of including metonymy in the analysis of images of organization. With these reflections, he appeared to suggest that his metaphor analysis was incomplete. We took inspiration from this idea, as well as from work in linguistics and cognitive science suggesting that metonymy is a prime activity in thinking and imagining along with, or as part of, metaphors. In this paper, we detail the different ways in which metaphor and metonymy may interact and form images of organization. We formalize these interrelations in an analytical grid (see Tables 1 and 2), which captures the basic operations of metaphoricalmetonymic imagination. The value of the grid as a methodology is that it highlights different processes of imagination, as well as the images that they produce, depending on whether metonymy or metaphor is the starting point or main emphasis and whether the process of imagination entails bidirectionality and concreteness.

In addition, the grid provides practical detail for the idea of 'disciplined imagination' (Cornelissen, 2006; Weick, 1989), which has not yet been specified in a direct operational 
manner. With our analytical grid, we hope to have provided a specific methodological 'tool' that researchers can use to guide their imagination, or to assess the basis of images with which they are confronted. Researchers can use the grid to discover alternative vocabularies and ways of thinking about organizations, or to evaluate and assess the heuristic value of particular images. Importantly, we have demonstrated the usability of this grid for comparing images of organization more generally and to explain why some images are better equipped than others to imagine organizations in paradoxical or dialectical terms (see Smith \& Lewis, 2011; Putnam, 2013).

In this regard, our framework complements Morgan's work $(1986,1996)$ in that it allows researchers to study images of organizations in light of the dynamic interplay of these images' metaphorical and metonymic dimensions. Rather than focusing on single images, as object-like representations, we believe there is value in thinking about metaphors as a continuous, dynamic, and paradoxical interplay of imagination, in which new (metaphorical) associations are made, new details are (metonymically) elaborated, and the link between them progressively shifts our understanding (see also Putnam and Boys, 2006).

Second, by applying the grid, we contribute to unpacking the entity-process paradox in process organization research (see Bakken and Hernes, 2006; Hernes and Weik, 2007a). Imagining organizations as processual phenomena (see also Morgan's notion, 1986, of the 'organization as flux and transformation') presumes a somewhat paradoxical relation between the organization as entity and as process: how can the fluid (process) constitute the comparably solid (entity), and how can something solid even be recognized in a fluid process? In this paper, we directly address Hernes and Weik's (2007a) call to further unpack the subtleties of this paradox. While we do not suggest that we have dissolved the paradox, our study provides a more detailed understanding of the pathways of imagination how processes and organizations may 
coevolve and coconstitute each other. This detail, as we have demonstrated, comes from pushing our understanding of process images beyond seeing them simply as metaphors. Instead, we highlight the value of analyzing process images regarding the interplay between metonymy and metaphor as a way of understanding the relations between specific details and the larger whole that are both 'at rest' and 'in flux.' As our study aims to have shown, the combination of metonymy and metaphor provides a useful explanatory framework for comparing different images regarding their ability to understand the paradoxical notion of organization as process.

By employing our analytical grid, we have added to the literature a novel and detailed metaphorical-metonymic analysis of flux-based images of organization. Since Morgan's work, flux-based images have become a mainstay of organizational scholarship (e.g., Hernes, 2014; Langley et al., 2013; Tsoukas and Chia, 2002), but have not, with the exception of Morgan's own writings, been analyzed in metaphorical and/or metonymic terms. This, we argue, has been a significant shortcoming, as the literature on process research is rife with metaphorical and figurative ways of thinking about organization and so would clearly benefit from such analysis. Our comparative analysis of three dominant offsprings of the flux image (organization as becoming, practice, and communication) suggests that the images scholars use are actually starkly different. Such a difference implies that there is a need for organizational scholars to acknowledge the figurative roots of different process images and then assess, based on their constituent details, what insights and inferences such images afford. With our analysis, we demonstrate not only that different process images afford different forms of imagination, but also that some are better equipped than others in capturing processes of organizing in dynamic, evolving, and concrete ways. For instance, we demonstrated that those images in which the metaphorical and metonymic dimensions were most closely interconnected (e.g., the $\mathrm{OaC}$ image) 
lend themselves particularly well to comprehend organizations as both processes and entities, because they embraced the dialectical tension between the poles (see Putnam, 2013).

\section{Practical implications}

Based on these theoretical contributions, our paper also offers a number of implications for organizational practitioners. In particular, we believe that our analytical grid, like Morgan's initial work $(1980,1986)$, can be insightful to practitioners as both a means of reflecting on their assumptions about organizations and of powering new ways of thinking and imagination. Our analytical grid, and more generally our reflections on the process of imagining organization, provide at least two insights for reflecting on one's images of organization. First, our grid can be useful to practitioners for reflecting about the images they draw on in their day-to-day activities, for instance, by sensitizing for the fact that imaginations tend to have not only a metaphorical but also a metonymic dimension (see also Morgan, 1996). For instance, we believe that our grid can be functional for managers as a means to illuminate the horizon of potential meanings of an image before actually applying it in practice. Such anticipatory ways of dealing with the process of imagining can be useful in practice, for example, in the context of change management (where metaphors tend to abound; see Dunford and Palmer, 1996; Marshak, 1993), especially in order to avoid that the use of images in organizational practices yields unintended and counterproductive effects (e.g., by neglecting the bulimic connotations that a term like 'lean organization' may evoke in the context of organizational restructuring; see Dunford and Palmer, 1996).

Second, our meta-theoretical reflection can also be seen as an invitation to imagine organization in paradoxical ways, and more particularly as both entity and process. The analysis of the three offsprings of the flux image reveals the advantages of embracing this paradox as it 
allows for a more dynamic understanding of the creation, transformation, and actual use of images in organization. For instance, the famous metaphor 'Who says that elephant can't dance?' by the former chairman and CEO of IBM, Louis Gerstner Jr., is a good example of an image that keeps the notion of entity (the organization as elephant) in a fruitful tension with process (change as a form of dance). In this respect, our analytical grid may help practitioners think about ways to redesign certain experiences for employees or strategically communicate 'metaphors within metonymies' that embrace the paradoxical nature of organization. 
${ }^{1}$ The empirical and theoretical approaches of 'organization as practice' present a very distinct view of the processentity relation. The empirical approach, the more prominent one in organization studies (in the literature known, for instance, under the label 'strategy as practice'; Golsorkhi et al., 2010) tends to analytically separate the entity (organization) and processes (practices). In the theoretical approach, as Feldman and Orlikowski (2011) aptly observe, the focus on the relationships and performances (processes) that constitute the organizational world and the analytical use of entities (genres, artifacts, routines) tend to blur the distinction between entity and process.

${ }^{2}$ Note that Smith's article relates to root metaphors that are used to describe the organization-communication relation. However, we believe that she developed a generic terminology that can also be used to describe other organization-process relations and their directionality.

${ }^{3}$ We will only consider the ontological (Schatzki, 2005, 2006) and theoretical (Feldman and Orlikowski, 2011) variants of the OaP image, because works following empirical variant do not tend to adopt a dialectical lens. 


\section{References}

Ashcraft KL, Kuhn TR and Cooren F (2009) Constitutional amendments: 'Materializing' organizational communication. Academy of Management Annals 3(1): 1-64.

Atkinson R, Crawford L, and Ward S (2006) Fundamental uncertainties in projects and the scope of project management. International Journal of Project Management 24 : 687-698.

Bakken T and Hernes T (2006) Organizing is both a verb and a noun: Weick meets Whitehead. Organization Studies 27(11): 1599-1616.

Bechky BA (2006) Gaffers, gofers, and grips: Role-based coordination in temporary organizations. Organization Science 17(1): 3-21.

Bencherki N and Cooren F (2011) Having to be: the possessive constitution of organization. Human Relations 64(12): 1579-1607.

Bjerregaard T and Jonasson C (2014) Managing unstable institutional contradictions: The work of becoming. Organization Studies 35(10): 1507-1536.

Blaschke S, Schoeneborn D and Seidl D (2012) Organizations as networks of communication episodes: Turning the network perspective inside out. Organization Studies 33(7): 879-906.

Blomquist T, Hällgren M, Nilsson A and Söderholm A (2010) Project-as-practice: In search of project management research that matters. Project Management Journal 41(1): 5-16.

Brummans B, Cooren F, Robichaud D and Taylor JR (2014) Approaches in research on the communicative constitution of organizations. In: Putnam LL, Mumby DK (eds) SAGE Handbook of Organizational Communication, 3rd edn. London: Sage, 173-194.

Burrell G and Morgan G (1979) Sociological paradigms and organizational analysis. London: Heinemann.

Chia R (1995) From modern to postmodern organizational analysis. Organization Studies 16(4): 579-604.

Chia, R (2005) Organization theory as a postmodern science. In: Tsoukas H, Knudsen C (eds) The Oxford handbook of organization theory. Oxford UK: Oxford University Press, 113-140.

Chia R and MacKay B (2007) Post-processual challenges for the emerging strategy-as-practice perspective: Discovering strategy in the logic of practice. Human Relations, 60(1), 217-242.

Clegg SR, Kornberger M and Rhodes C (2005) Learning/becoming/organizing. Organization 12(2): 147-167.

Cooren F (2000) The organizing property of communication. Amsterdam: John Benjamins.

Cooren F (2010) Action and agency in dialogue: Passion, incarnation and ventriloquism. Amsterdam: John Benjamins. 
Cooren F (2012) Communication theory at the center: Ventriloquism and the communicative constitution of reality. Journal of Communication 62(1): 1-20.

Cooren F and Taylor JR (1997) Organization as an effect of mediation: Redefining the link between organization and communication. Communication Theory 7(3): 219-260.

Cooren F, Brummans BH and Charrieras D (2008) The coproduction of organizational presence: A study of Médecins Sans Frontières in action. Human Relations 61(10): 1339-1370.

Cooren F, Kuhn TR, Cornelissen JP and Clark T (2011) Communication, organizing, and organization. Organization Studies 32(9): 1149-1170.

Cornelissen JP (2005) Beyond compare: Metaphor in organization theory. Academy of Management Review 30(4): 751-764.

Cornelissen JP (2006) Making sense of theory construction: Metaphor and disciplined imagination. Organization Studies 27(11): 1579-1597.

Cornelissen JP (2008) Metonymy in language about organizations: A corpus-based study of company names. Journal of Management Studies 45(1): 79-99.

Craig RT (1999) Communication theory as a field. Communication Theory 9(2): 119-161.

Deignan A (2005) Metaphor and corpus linguistics. Amsterdam: John Benjamins.

Deignan A and Potter L (2004) A corpus study of metaphors and metonyms in English and Italian. Journal of Pragmatics 36: 1231-1252.

Demir R and Lychnell LO (2015) Mangling the process: A meta-theoretical account of process theorizing. Qualitative Research 15(1): 85-104.

Dobusch L and Schoeneborn D (forthcoming) Fluidity, identity, and organizationality: The communicative constitution of Anonymous. Journal of Management Studies.

Dunford R and Palmer I (1996) Metaphors in popular management discourse: The case of corporate restructuring. In: Grant D, Oswick C (eds) Metaphor and organizations. London: Sage, 95-109.

Eco U (1979) The role of the reader. Bloeomington, IN: Indiana University Press.

Fairhurst GT and Putnam LL (1999) Reflections on the organization-communication equivalency question: The contributions of James Taylor and his colleagues. Communication Review 3(1-2): $1-19$.

Fairhurst GT and Putnam LL (2004) Organizations as discursive constructions. Communication Theory 14(1): 5-26.

Feldman MS and Orlikowski WJ (2011) Theorizing practice and practicing theory. Organization Science 22(5): 1240-1253. 
Gibbs, RW (2006) Embodiment and cognitive science. Cambridge, UK: Cambridge University Press.

Golsorkhi D, Rouleau L, Seidl D, Vaara E (eds) (2010) Cambridge handbook of strategy as practice. Cambridge, UK: Cambridge University Press.

Goossens L (1990) Metaphtonomy: The interaction of metaphor and metonymy in expressions for linguistic action. Cognitive Linguistics 1: 323-340.

Goossens L (1995a) Metaphtonomy: The interaction of metaphor and metonymy in expressions for linguistic action. In: Goossens L, et al. (eds) By word of mouth: Metaphor, metonymy and linguistic action in a cognitive perspective. Amsterdam: John Benjamins, 159-174.

Goossens L (1995b). From three respectable horses' mouths: Metonymy and conventionalization in a diachronically differentiated database. In Goossens L, et al. (eds) By word of mouth: Metaphor, metonymy and linguistic action in a cognitive perspective. Amsterdam: John Benjamins, 175-204.

Green S, Alpaslan C and Mitroff I (2010) Organizational inquiry as a rhetorical process: The role of tropes in organizational science. Electronic Journal of Business Research Methods 8(1): 4762.

Helin J, Hernes T, Hjorth D and Holt R (eds) (2014) The Oxford handbook of process philosophy and organization studies. Oxford, UK: Oxford University Press.

Hernes T (2014) A process theory of organization. Oxford, UK: Oxford University Press.

Hernes T and Weik E (2007a) Organization as process: Drawing a line between endogenous and exogenous views. Scandinavian Journal of Management 23(3): 251-264.

Hernes T and Weik E (2007b) Towards a theory of organizational becoming. In: Lang R, Schmitt A (eds) Individuum und Organisation. Wiesbaden: DUV, 73-95.

Jakobson R (1956/1990) Two aspects of language and two types of aphasic disturbances. In: Waugh LR, Monville-Burston M (eds) On language/Roman Jakobson. Cambridge, MA: Harvard University Press, 115-133.

Jarzabkowski P (2008) Strategy as practice. In: Barry D, and Hansen H (eds) The Sage handbook of new and emerging approaches to management and organization. London, UK: Sage, 364-379.

King BG, Felin T and Whetten DA (2010) Finding the organization in organizational theory: A meta-theory of the organization as a social actor. Organization Science 21(1): 290-305.

Kuhn T (2012) Negotiating the micro-macro divide thought leadership from organizational communication for theorizing organization. Management Communication Quarterly 26(4): 543584 .

Lakoff G and Johnson M (1980) Metaphors we live by. Chicago, IL: University of Chicago Press. 
Langley A, Smallman C, Tsoukas H and Van de Ven AH (2013) Process studies of change in organization and management: Unveiling temporality, activity, and flow. Academy of Management Journal 56(1): 1-13.

Lodge D (1977) The modes of modern writing: Metaphor, metonymy, and the typology of modern literature. Ithaca; NY: Cornell University Press.

Luhmann N (2003) Organization. In: Bakken T, Hernes T (eds) Autopoietic organization theory: Drawing on Niklas Luhmann's social systems perspective. Copenhagen: Copenhagen Business School Press, 31-52.

McPhee RD and Zaug P (2000) The communicative constitution of organizations: A framework for explanation. Electronic Journal of Communication/La Revue Electronique de Communication 10(1-2): 1-16.

Manning PK (1979) Metaphors of the field: Varieties of organizational discourse. Administrative Science Quarterly 24: 660-671.

Marshak RJ (1993) Managing the metaphors of change. Organizational Dynamics 22(1): 44-56.

Miettinen R, Samra-Fredericks D and Yanow D (2009). Re-turn to practice: An introductory essay. Organization Studies 30(12): 1309-1327.

Morgan G (1980) Paradigms, metaphors and puzzle solving in organizational theory. Administrative Science Quarterly 25: 605-622.

Morgan G (1983) More on metaphor: Why we cannot control tropes in administrative science. Administrative Science Quarterly 28: 601-607.

Morgan G (1986) Images of organization. Beverly Hills, CA: Sage.

Morgan G (1996) Is there anything more to be said about metaphor? In: Grant D, Oswick C (eds) Metaphor and organizations. London: Sage, 227-240.

Musson, G and Tietze S (2004) Places and spaces: The role of metonymy in organizational talk. Journal of Management Studies 41: 1301-1323.

Nicolini D (2009) Zooming in and out: Studying practices by switching theoretical lenses and trailing connections. Organization Studies 30(12): 1391-1418.

Nicolini D (2013) Practice theory, work, and organization: An introduction. Oxford, UK: Oxford University Press.

Nicotera AM (2013) Organizations as entitative beings: Some ontological implications of communicative constitution. In: Robichaud D, Cooren F (eds) Organization and organizing: Materiality, agency, and discourse. New York: Routledge, 66-89.

O'Mahony S and Ferraro F (2007) The emergence of governance in an open source community. Academy of Management Journal 50(5): 1079-1106. 
Orlikowski WJ (2007) Sociomaterial practices: Exploring technology at work. Organization studies 28(9): 1435-1448.

Oswick C, Keenoy T and Grant D (2002) Metaphor and analogical reasoning in organization theory: Beyond orthodoxy. Academy of Management Review 27: 294-303.

Oswick C, Putnam LL and Keenoy T (2004) Tropes, discourse and organizing. In: Grant D, Hardy C, Oswick C, Putnam LL (eds) The Sage handbook of organizational discourse. Thousand Oaks, CA: Sage, 105-128.

Poole MS and Van de Ven AH (1989) Using paradox to build management and organization theories. Academy of Management Review 14(4): 562-578.

Putnam LL (2013) Dialectics, contradictions, and the question of agency: A tribute to James R. Taylor. In: Robichaud D, Cooren F (eds) Organization and organizing: Materiality, agency, and discourse. New York: Routledge, 23-36.

Putnam LL, Phillips N and Chapman P (1996) Metaphors of communication and organization. In: Clegg SR, Hardy C, Nord WR (eds) Handbook of organizational studies. London: Sage, 375408.

Putnam LL and Boys S (2006) Revisiting metaphors of organizational communication. In: Clegg SR, Hardy C, Lawrence TB, Nord WR (eds) Sage handbook of organization studies. London: Sage, 541-576.

Putnam LL and Nicotera AM (2009) Building theories of organization: The constitutive role of communication. Oxford, UK: Routledge.

Rescher N (2000) Process philosophy: A survey of basic issues. Pittsburgh, PA: University of Pittsburgh Press.

Riad S and Vaara E (2011) Varieties of national metonymy in media accounts of international mergers and acquisitions. Journal of Management Studies 48(4): 737-771.

Robichaud D and Cooren F (eds) Organization and organizing: Materiality, agency, and discourse. New York: Routledge.

Robichaud D, Giroux H and Taylor JR (2004) The metaconversation: The recursive property of language as a key to organizing. Academy of Management Review 29: 617-634.

Schatzki TR (2005) The sites of organizations. Organization Studies 26(3): 465-484.

Schatzki TR (2006) On organizations as they happen. Organization Studies 27(12): 1863-1873.

Schatzki TR, Knorr-Cetina K and von Savigny E (eds) (2001) The practice turn in contemporary theory. East Sussex, UK: Psychology Press.

Schoeneborn D, Blaschke S and Kaufmann IM (2013) Recontextualizing anthropomorphic metaphors in organization studies: The pathology of organizational insomnia. Journal of Management Inquiry 22(4) : 435-450. 
Searle JR (1979) Metaphor. In: Ortony A (ed) Metaphor and thought. Cambridge, UK: Cambridge University Press, 92-123.

Shepherd DA and Sutcliffe KM (2015) The use of anthropomorphizing as a tool for generating organizational theories. Academy of Management Annals 9(1): 97-142.

Sillince JAA and Barker JR (2011) A tropological theory of institutionalization. Organization Studies 33: 7-38.

Smith RC (1993) Images of organizational communication: Root-metaphors of the organizationcommunication relation. Paper presented at the International Communication Association conference, Washington, DC.

Smith WK and Lewis MW (2011) Toward a theory of paradox: A dynamic equilibrium model of organizing. Academy of Management Review 36(2): 381-403.

Spence C and Thomson I (2009) Resonance tropes in corporate philanthropy discourse. Business Ethics: A European Review 18(4): 372-388.

Spender JC (1996) Organizational knowledge, learning and memory: Three concepts in search of a theory. Journal of Organizational Change Management 9: 63-78.

Stengers I (2005) Whitehead's account of the sixth day. Configurations 13: 35-55.

Sydow J, Schreyögg G and Koch J (2009).Organizational path dependence: Opening the black box. Academy of Management Review 34(4): 689-709.

Taylor JR (2003) Organizational communication: Is it a discipline? Inaugural lecture as Kurt Baschwitz Professor at the University of Amsterdam, June 12, 2003.

Taylor JR (2011) Organization as an (imbricated) configuring of transactions. Organization Studies 32(9): 1273-1294.

Taylor JR and Cooren F (1997) What makes communication 'organizational'? How the many voices of a collectivity become the one voice of an organization. Journal of Pragmatics 27(4): 409-438.

Taylor JR and Van Every EJ (2000) The emergent organization: Communication as its site and surface. New York: Erlbaum.

Taylor JR, Cooren F, Giroux N and Robichaud D (1996) The communicational basis of organization: Between the conversation and the text. Communication Theory 6(1): 1-39.

Tsoukas H (1991) The missing link: A transformational view of metaphors in organizational science. Academy of Management Review 16: 566-585.

Tsoukas H (1993) Analogical reasoning and knowledge generation in organization theory. Organization Studies 14(3): 323-346.

Tsoukas H and Chia R (2002) On organizational becoming: Rethinking organizational change. Organization Science 13(5): 567-582. 
Vaara E and Whittington R (2012) Strategy-as-practice: taking social practices seriously. Academy of Management Annals 6(1): 285-336.

Vasquez C, Schoeneborn D and Sergi V (forthcoming) Summoning the spirits: Organizational texts and the (dis)ordering properties of communication. Human Relations.

Watson TJ (1995) Rhetoric, discourse and argument in organizational sense making: A reflexive tale. Organization Studies 16(5): 805-821.

Wee L (2005) Constructing the source: Metaphor as a discourse strategy. Discourse Studies 7: 363-384.

Weick KE (1979) The social psychology of organizing. New York: Random House.

Weick KE (1989) Theory construction as disciplined imagination. Academy of Management Review 14(4): 516-531.

Weick KE (2004) A bias for conversation: Acting discursively in organizations. In: Grant D, Hardy C, Oswick C, Putnam LL (eds) The Sage handbook of organizational discourse. Thousand Oaks, CA: Sage, 405-412.

Weick KE and Quinn RE (1999) Organizational change and development. Annual Review of Psychology 50(1) : 361-386.

Weick KE and Roberts K (1993) Collective mind in organizations: Heedful interrelating on flight decks. Administrative Science Quarterly 38(3): 357-381.

Whetten DA (2006) Albert and Whetten revisited: Strengthening the concept of organizational identity. Journal of Management Inquiry 15(3): 219-234.

Winter M, Smith C, Morris P and Cicmil S (2006) Directions for future research in project management: The main finding of a UK government-funded research network. International Journal of Project Management 24: 638-649. 
Table 1: Analytical grid for studying metaphor-metonymy relations

\begin{tabular}{|l|l|}
\hline Dimensions & Definition \\
\hline (1) Type of metaphor- & $\begin{array}{l}\text { The dynamics characterizing the relationship between } \\
\text { metaphor and metonymy. Two types of relations can be } \\
\text { distinguished (see also Goossens, 1995a): } \\
\text { (1a) 'Metonymy within metaphor': the process of imagination } \\
\text { starts with a metaphor and follows with the details of the } \\
\text { metonymic interpretation. } \\
\text { (1b) 'Metaphor from metonymy': the process of imagination } \\
\text { starts with a metonymy and follows with a metaphorical } \\
\text { interpretation. }\end{array}$ \\
\hline $\begin{array}{l}\text { (2) Directionality of the } \\
\text { process of imagination } \\
\text { work in two ways (either unidirectional or bidirectional): } \\
\text { (2a) Directionality of the metaphorical (horizontal) dimension: } \\
\text { Imagining the target domain in terms of the source domain } \\
\text { and/or vice versa. } \\
\text { (2b) Directionality of the metonymic (vertical) dimension: } \\
\text { constitutive elements stand in for the whole (pars pro toto) } \\
\text { and/or the whole stands in for the constitutive elements (totum } \\
\text { pro parte). }\end{array}$ \\
\hline $\begin{array}{l}\text { The capacity of the process of imagination and the resulting } \\
\text { figure to represent an abstract idea or phenomenon in more } \\
\text { concrete ways. Concreteness can work in two ways: } \\
\text { (3a) Degree of concreteness of the source domain or } \\
\text { constitutive elements: an abstract and larger idea or } \\
\text { phenomenon is understood by referring to a more particular } \\
\text { and concrete source domain (metaphorically) or to constitutive } \\
\text { elements (metonymically). } \\
\text { (3b) Degree of concreteness of the resulting figure: the } \\
\text { resulting figure that connects source and target domains is } \\
\text { more or less concrete, i.e., accessible to direct and sensual } \\
\text { experiences. }\end{array}$ \\
\hline
\end{tabular}


Table 2: Metaphor-metonymy analysis of the three offsprings of the flux image

\begin{tabular}{|c|c|c|c|}
\hline & $\begin{array}{c}\text { Organization } \\
\text { as becoming }\end{array}$ & $\begin{array}{c}\text { Organization } \\
\text { as practice }\end{array}$ & $\begin{array}{l}\text { Organization as } \\
\text { communication }\end{array}$ \\
\hline $\begin{array}{l}\text { Source concept } \\
\text { of the image }\end{array}$ & $\begin{array}{l}\text { Becoming = perpetual } \\
\text { process of change } \\
\text { (Tsoukas and Chia, 2002: } \\
576 \text { ) }\end{array}$ & $\begin{array}{l}\text { Practice }=\text { embodied } \\
\text { and materially mediated } \\
\text { arrays of human activity } \\
\text { (Schatzki et al., 2001: } \\
\text { 11) }\end{array}$ & $\begin{array}{l}\text { Communication }= \\
\text { complex and dynamic } \\
\text { process of meaning } \\
\text { negotiation (Ashcraft et } \\
\text { al., 2009: 22) }\end{array}$ \\
\hline $\begin{array}{l}\text { Examples of empirical } \\
\text { studies following the } \\
\text { image }\end{array}$ & $\begin{array}{l}\text { Bjerregaard and Jonasson } \\
\text { (2014); Sergi (2012) }\end{array}$ & $\begin{array}{l}\text { Atkinson et al. (2006); } \\
\text { Bechky (2006); Nicolini } \\
(2009)\end{array}$ & $\begin{array}{l}\text { Blaschke et al. (2012); } \\
\text { Vasquez et al. (2015) }\end{array}$ \\
\hline \multicolumn{4}{|c|}{ Analytical grid for studying metaphor-metonymy relations } \\
\hline $\begin{array}{l}\text { (1) Metaphor- } \\
\text { metonymy dynamics }\end{array}$ & $\begin{array}{l}\text { Metonymy within } \\
\text { metaphor (metaphor as } \\
\text { the main driver) }\end{array}$ & $\begin{array}{l}\text { Metaphor from } \\
\text { metonymy (metonymy } \\
\text { as the main driver) }\end{array}$ & $\begin{array}{l}\text { Metaphor from } \\
\text { metonymy (metonymy } \\
\text { as the main driver) }\end{array}$ \\
\hline $\begin{array}{l}\text { (2a) Metaphorical } \\
\text { (horizontal) } \\
\text { directionality }\end{array}$ & $\begin{array}{l}\text { Primarily unidirectional } \\
\text { (understanding } \\
\text { organization through a } \\
\text { becoming lens) }\end{array}$ & $\begin{array}{l}\text { Primarily unidirectional } \\
\text { (understanding } \\
\text { organization through a } \\
\text { practice lens) }\end{array}$ & $\begin{array}{l}\text { Bidirectional } \\
\text { (understanding } \\
\text { organization through a } \\
\text { communication lens, } \\
\text { and vice versa) }\end{array}$ \\
\hline $\begin{array}{l}\text { (2b) Metonymic } \\
\text { (vertical) } \\
\text { directionality }\end{array}$ & $\begin{array}{l}\text { Partly bidirectional } \\
\text { (coproduction) }\end{array}$ & $\begin{array}{l}\text { Strongly bidirectional } \\
\text { (equivalence) }\end{array}$ & $\begin{array}{l}\text { Strongly bidirectional } \\
\text { (equivalence) }\end{array}$ \\
\hline $\begin{array}{l}\text { (3a) Degree of } \\
\text { concreteness of the } \\
\text { source domain }\end{array}$ & $\begin{array}{l}\text { Becoming as an abstract } \\
\text { and generic form of } \\
\text { process }\end{array}$ & $\begin{array}{l}\text { Practice as a more } \\
\text { concrete form of } \\
\text { process (material, } \\
\text { embodied, and } \\
\text { observable) }\end{array}$ & $\begin{array}{l}\text { Communication as a } \\
\text { more concrete form of } \\
\text { process and practice } \\
\text { (material, embodied, } \\
\text { and observable) }\end{array}$ \\
\hline $\begin{array}{l}\text { (3b) Degree of } \\
\text { concreteness of the } \\
\text { target domain }\end{array}$ & $\begin{array}{l}\text { Rather abstract notion of } \\
\text { organization as emergent } \\
\text { order }\end{array}$ & $\begin{array}{l}\text { Rather abstract notion } \\
\text { of organization as } \\
\text { bundle or mesh of } \\
\text { practices }\end{array}$ & $\begin{array}{l}\text { More concrete, } \\
\text { anthropomorphized } \\
\text { notion of organization } \\
\text { as (macro) actor }\end{array}$ \\
\hline \multicolumn{4}{|c|}{ Forms of dealing with the process-entity paradox } \\
\hline $\begin{array}{l}\text { Type of dialectical } \\
\text { thinking (drawing on } \\
\text { the terminology by } \\
\text { Putnam, 2013) }\end{array}$ & $\begin{array}{l}\text { Selection: obscuring the } \\
\text { opposition by choosing } \\
\text { one pole (process) as the } \\
\text { primary (e.g., Tsoukas } \\
\text { and Chia, 2002) }\end{array}$ & $\begin{array}{l}\text { Separation: recognizing } \\
\text { both poles, but } \\
\text { collapsing the macro } \\
\text { (entity) into the micro } \\
\text { (practice) (e.g., } \\
\text { Schatzki, 2005, 2006) }\end{array}$ & $\begin{array}{l}\text { Connection: embracing } \\
\text { the opposition (e.g., } \\
\text { Bencherki and Cooren, } \\
2011 \text {; Dobusch and } \\
\text { Schoeneborn, } \\
\text { forthcoming) }\end{array}$ \\
\hline
\end{tabular}


Figure 1: Types of metaphor-metonymy dynamics

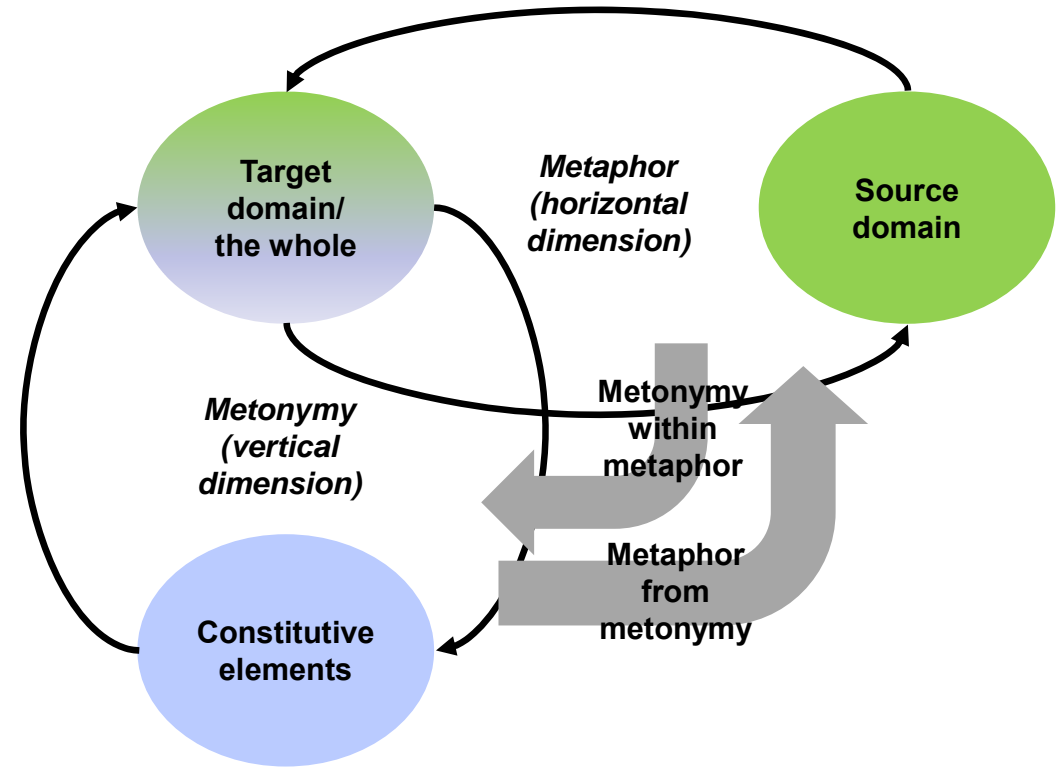

Figure 2: Horizontal and vertical directionality of the process of imagination

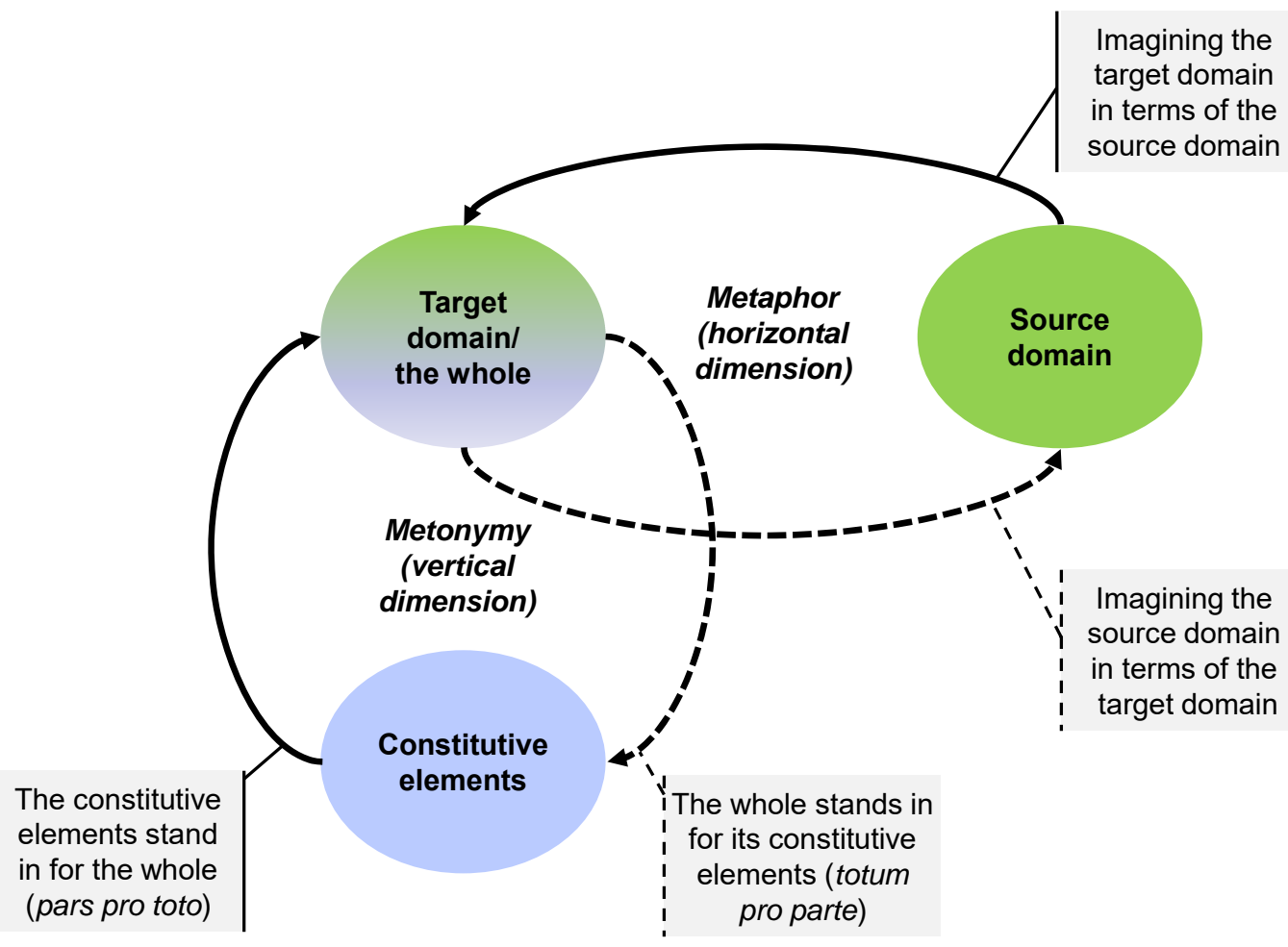

